\title{
Comunicación

\section{Periodismo en entornos violentos: el caso de los periodistas de Culiacán, Sinaloa ${ }^{1}$}

\author{
FRIDA VIRIDIANA RODELO2
}

El artículo analiza las limitaciones de la práctica del periodismo en una región de México con alta incidencia de violencia: la ciudad de Culiacán. Se sostiene que tanto la violencia como las limitaciones del periodismo se asocian con la debilidad del Estado mexicano. Finalmente, se propone una definición del periodismo precavido practicado por los periodistas del lugar - un periodismo sobre temas delicados-, definido por condiciones económicas y de seguridad.

PALABRAS CLAVE: libertad de prensa, cobertura de la violencia, periodismo en entornos violentos, periodismo seguro.
The article presents an analysis of the limitations in the practice of journalism in a region of Mexico that has a high incidence of violence -the city of Culiacan, in the northwest. It argues that violence as much as journalistic limitations are associated with the weakness of the Mexican State. Finally, it proposes a category of 'cautious journalism' based in the local journalists 'practices-journalism about sensitive topics, defined by economic and security terms.

KEYWORDS: freedom of the press, media coverage of violence, journalism in dangerous environments, news safety.

1 Este artículo se basa en la tesis de maestría "Ejercicio de la libertad de prensa y sus limitaciones en entornos violentos. El caso de los periodistas de Culiacán, Sinaloa, México”, Maestría en Ciencias Sociales, Universidad de Guadalajara, Guadalajara, 2008.

2 Universidad de Guadalajara, México.

Correo electrónico: viri.rodelo@gmail.com 


\section{INTRODUCCIÓN}

La libertad de prensa en México es difícil de clasificar. En las grandes metrópolis mexicanas puede considerarse que los periodistas disfrutan de una libertad de prensa en un ambiente de relativo respeto: los incidentes de violencia contra periodistas son raros, tienen libertad de elegir los temas que pueden abordar a través de los medios de comunicación y tienen criterios éticos que distinguen entre "buenas" y "malas" prácticas periodísticas. Sin embargo, en gran parte de las regiones del interior del país - principalmente aquellas con presencia importante de grupos de crimen organizado y grandes tasas de crímenes de alto impacto- los periodistas ejercen el periodismo con severas limitaciones, hostigamientos y casos frecuentes de violencia física o verbal. Este artículo aborda el caso de la ciudad de Culiacán: ¿cómo es limitado el ejercicio de la libertad de prensa de los periodistas de esta ciudad? A partir de la idea de que los fenómenos de violencia y las limitaciones del periodismo se asocian con la debilidad del Estado, se propone en este trabajo una caracterización del periodismo precavido, practicado por los periodistas de Culiacán. Este tipo de periodismo se caracteriza por abordar temas delicados y es definido por las condiciones económicas $\mathrm{y}$ de seguridad del entorno.

\section{LIBERTAD DE PRENSA EN DEMOCRACIAS DÉBILES:}

EL CASO DE MÉXICO

La libertad de prensa es un derecho individual y colectivo al mismo tiempo. La interpretación de cómo se puede ejercer la libertad de prensa está íntimamente relacionada con el tipo de régimen político imperante: desde el autoritarismo (donde tiende a limitar) hasta el liberalismo (donde tiende a desregular). En Four Theories of the Press los estadounidenses Siebert et al. (1963) propusieron que el ejercicio del periodismo debería ser de "responsabilidad social".

Al relacionar los tipos de regímenes políticos con los tipos de ejercicio de la libertad de prensa, resulta apropiado considerar a algunos países como democracias débiles o en tránsito. Para Carlos Flores (2005: $4,16)$, en los Estados débiles hay una diferencia entre las normas ins- 
titucionales formales y las normas institucionalizadas por las prácticas sociales, así como una falta de diferenciación entre intereses públicos y privados. Waisbord (2002: 93) encuentra el fenómeno de debilidad del Estado en la incapacidad de monopolizar el uso de la fuerza y en la impunidad de los responsables de los ataques contra periodistas. Además, en este tipo de regímenes el gobierno tiene influencia sobre los medios debido a razones de índole política o económica, aunque no haya coerción abierta contra los periodistas. Sobre este aspecto, Jean K. Chalaby (2000: 21-22) encuentra cuatro tipos de censura: las de carácter legal, administrativo, violento y económico. El tipo de censura violenta es un tema de preocupación en las naciones con regímenes autoritarios y en las democracias débiles, como es el caso de los países latinoamericanos, sobre los cuales Waisbord (2002: 93-94) ha observado que la violencia contra periodistas no parece separada de la violencia en general.

En cuanto al caso mexicano, podemos ubicar, a partir del siglo XX, dos etapas del ejercicio de la libertad de prensa de los periodistas. Sobre la primera de ellas, los autores describen el tipo de ejercicio periodístico que se realizaba en la etapa posrevolucionaria mexicana, denominándole, por ejemplo, de "subordinación de los medios al poder público" a través de diferentes medidas jurídicas, políticas y económicas (Carreño 2000). Por otra parte, varios académicos coinciden en identificar un periodo de "apertura" o de "mayor" libertad de prensa a partir de las décadas de 1960 (Acosta, 1994), 1970 (Carreño ibid) y 1980, con la publicación de revistas y periódicos como Siempre!, el Excélsior previo a 1976, Proceso, La Jornada y, ya en la década de 1990, El Norte, Reforma (Hughes, 2003), y el diario matutino jalisciense Siglo 21.

Raúl Trejo Delarbre (1995) hizo notar, sin embargo, las paradojas que seguían existiendo en el periodismo mexicano y que pueden considerarse factores de limitación del ejercicio de la libertad de prensa: escasez de lectores, manipulación de cifras sobre circulación, discrecionalidad oficial en el otorgamiento de publicidad y presiones políticas y económicas. Las investigaciones y los reportes que se han realizado sobre periodismo en las regiones de México (Martínez et al., 1994; FMB, 1997; Orozco 2007) aportan pruebas de que los problemas mencionados por Trejo (1995) siguen afectando el ejercicio periodístico, por lo menos en el interior del país. 
Aunado a lo anterior, la Fundación Manuel Buendía, interesada en el tema de la violencia contra periodistas, comenzó a emitir desde 1988 informes anuales sobre la situación de la libertad de prensa en el país. En uno de ellos, este organismo no gubernamental (Martínez et al., 1994) refiere que la cantidad de periodistas asesinados en México ascendió durante cada sexenio, desde el periodo de Luis Echeverría (1970-1976, seis periodistas victimados) hasta el de Carlos Salinas (1988-1994, 46 periodistas victimados). Article 19 et al. (2008: 7) refieren que durante el sexenio de Vicente Fox (2000-2006) 16 periodistas fueron asesinados. A las cifras de tales homicidios hay que añadir los casos de agresiones físicas, amenazas y otras formas de intimidación, los cuales han aumentado en el estado de Sinaloa y en otras partes de la República Mexicana donde operan el crimen organizado así como -después de 2006- estrategias de militarización de la seguridad pública.

La libertad de prensa en México, en la década de 2000, presenta contrastes que se deben contextualizar. Aunque en las tres ciudades más importantes del país se asumen condiciones de libertad de prensa, México continúa apareciendo en los listados de los países más letales para los periodistas en el mundo. Reporteros sin Fronteras (2008) señala que en 2008 México fue el cuarto país en el planeta con mayor cantidad de homicidios de periodistas (cuatro casos), sólo superado por Irak, Paquistán y Filipinas. ${ }^{3}$ El periodista Ignacio Rodríguez Reyna, en el informe de la Red Periodismo de Calidad (2006: 11), intentó explicar lo anterior al afirmar que "Ni la calidad de la democracia ni la del periodismo que existen en el país han llegado a los niveles que caracterizan a las sociedades democráticas avanzadas". Sin embargo, sostuvo que en México:

Hoy, los periodistas tienen una mayor preparación educativa, disponen de más y mejores herramientas tecnológicas, cuentan con un mayor acceso a la información pública y ejercen su actividad profesional en un ambiente en el

3 En 2006, México fue catalogado por Reporteros sin Fronteras (2006) como el segundo país más peligroso para los periodistas en el mundo. Su índice de libertad de prensa se basó en el registro de incidentes violentos en contra de reporteros, entre ellos nueve homicidios dolosos, ocurridos principalmente en el interior del país. 
que, por lo general y sin descartar excepciones, la libertad de expresión es muy amplia (ibidem: 10).

¿Qué factores ocasionan el contraste entre el ambiente de peligrosidad para los periodistas del interior y el ambiente de libertad de prensa de las principales zonas metropolitanas del país descrito por Rodríguez Reyna? Este contraste dificulta una definición del nivel de libertad de prensa en México, por lo cual resulta pertinente preguntarse cuáles son las características de las limitantes de la libertad de prensa en el periodismo mexicano, considerando el contexto particular de las regiones en las que se practica-por ejemplo, grandes metrópolis versus interior del país.

Las limitantes del ejercicio de la libertad de prensa incluyen los casos de amagos contra los periodistas y las diferentes actitudes que estas agresiones acarrean. Además, ocurren situaciones al margen de lo registrable en los reportes de las asociaciones de periodistas, en las que los límites de la libertad de prensa se manifiestan de forma más sutil, como es el caso de la autocensura y la disminución del periodismo crítico y de denuncia ocasionadas por temor a represalias, respeto excesivo a la autoridad y presiones institucionales. La libertad de prensa -en su sentido colectivo-también puede ser limitada a consecuencia de la falta de interés social por parte de los medios informativos o periodistas.

Los principales factores de vulnerabilidad para los periodistas son, para Silvio Waisbord (2002: 96), cubrir temas delicados y reportar para la prensa local -la nacional suele ser menos vulnerable. Además, en la medida en que las organizaciones criminales (en particular las de narcotráfico) gozan de poder en la región, aumenta el peligro a que se exponen las organizaciones periodísticas al pretender dar una cobertura no oficial o investigar sobre fenómenos criminales.

\section{LOS PERIODISTAS DE CULIACÁN}

El caso de los periodistas de la ciudad de Culiacán, capital del estado mexicano de Sinaloa, al noroeste del país, resulta particular por desenvolverse en una zona del interior del país donde ocurren diversos tipos de limitaciones a la libertad de prensa. Sinaloa es la entidad con mayor 
número de homicidios dolosos cometidos (ajuste de cuentas por bandas del crimen organizado: 476 "homicidios" en 2007) (López, 2008). 4 La ciudad de Culiacán presenta una aguda problemática de violencia relacionada con estos. Además, existen indicios de corrupción de elementos de las corporaciones de seguridad pública, como ha quedado demostrado con los frecuentes escándalos de corrupción policiaca, y el involucramiento de sectores políticos, económicos y civiles con actividades de tráfico de sustancias ilícitas. La región es un importante centro de producción y de operaciones de líderes de traficantes, lugar de origen de familias y pueblos relacionados con tal actividad, así como de retenes militares y donde bandas rivales escenifican violentos enfrentamientos. Con este contexto, la población de Culiacán demanda información sobre temas de violencia y seguridad. Como lo señaló un informante para esta investigación: "en entidades como Sinaloa y en ciudades como Culiacán es imposible no escribir del narco".5

En el marco del auge del tráfico ilegal de sustancias, el periodismo se ejerce con severas limitaciones y autocensura. El caso extremo de crimen contra la libertad de prensa, el asesinato de periodistas, ha estado presente desde el inicio de los registros mexicanos de este tipo de agresiones. El más reciente fue el homicidio del fotorreportero Gregorio Rodríguez, en 2004, en el que resultaron involucrados jefes policiacos coludidos con traficantes.

Los fenómenos de limitación del ejercicio de la libertad de prensa han sido denunciados por la propia prensa o por organismos civiles (FMB, 2006; Trotti, 2006; CPJ, 2006). Algunos reportes sobre libertad de prensa han señalado que entre los tipos de limitaciones del ejercicio periodístico destacan las presiones políticas y las presiones económicas (RPC, 2006).

Para realizar el análisis de las limitaciones del ejercicio de la libertad de prensa de los periodistas de Culiacán fue preciso considerar el aspecto contextual, abordar el fenómeno de esas limitaciones en Culiacán, descomponiéndolo en distintos niveles, dimensiones y mediaciones, tal

4 El cultivo, procesamiento y tráfico de marihuana y amapola comenzó en la entidad desde antes de la década de 1970; los grupos de traficantes de esta región fueron pioneros en esta actividad a nivel nacional (cfr. Astorga, 2005).

5 Entrevista con D1, periodista de Río Doce, 2008. 
como lo plantea Enrique Sánchez Ruiz (1992: 79-82) en su método histórico estructural. Se partió de tres ejes hipotéticos de limitaciones de la libertad de prensa: la economía de la prensa, la relación prensa-poder y el entorno de violencia. 6 Otro aspecto económico que funge como factor de limitación de la libertad de prensa, los conflictos de interés, los encontramos en este estudio de caso en la discrecionalidad gubernamental para contratar publicidad.

La técnica que se utilizó fue la entrevista semiestructurada, a partir de la cual reunimos testimonios de ocho periodistas de Culiacán sobre los ejes "relación prensa-poder" y "entorno de violencia”. El monitoreo y la recolección de notas de los medios impresos de la ciudad de $\mathrm{Cu}$ liacán permitieron ampliar y contextualizar la información contenida en los testimonios. La hipótesis de partida fue que el ejercicio de la libertad de prensa de los periodistas de Culiacán se encuentra limitado por las características económicas de las empresas periodísticas, la relación prensa-poder y el entorno de violencia y crimen organizado en la región. De esta manera, el poder del gobierno y del narcotráfico limita la libertad de prensa de los periodistas por causa del miedo y la dependencia económica de los medios en el gobierno del Estado.

Los antecedentes de la relación prensa-poder, en Culiacán, se encuentran ligados a los del resto de las regiones del país: como rasgo importante, los periódicos solían estar coludidos de alguna forma con los participantes

6 Posteriormente encontramos dificultades para separar los fenómenos de los ejes de "economía de la prensa" y "relación prensa-poder": resultó que no localizamos en la prensa escrita de la región algunos fenómenos, que señalamos como factores económicos, y que limitan la libertad de prensa a nivel mundial, nos referimos a la concentración de la propiedad de los medios (las siete publicaciones periódicas de Culiacán pertenecen a cuatro empresas, tres de ellas regionales) y el acceso elitista a los medios (el caso de los periodistas del semanario local Río Doce demuestra que las nuevas empresas pequeñas e independientes pueden subsistir, aunque con importantes problemas de financiamiento). No obstante, ambos fenómenos son, sin duda, típicos de la radio y la televisión en toda la nación mexicana. Por este motivo al final resultaron dos reportes: el de la relación prensa-poder como factor de limitación económica-política y el del entorno de la violencia. 
del sistema político durante el régimen autoritario posrevolucionario. En el caso de Culiacán, el periódico principal, en cuanto a su circulación, era parte de la cadena de medios pro gobiernista Organización Editorial Mexicana. Asimismo, era aceptable que los periodistas intercalaran en sus currículos su actividad profesional periodística con cargos en la administración pública, partidos políticos o cargos de elección popular. Sin embargo, a partir de la llegada de otros periódicos locales en la década de 1970, periodistas de estas nuevas empresas sostienen que hubo una noción menos oficialista sobre lo que debería ser la actividad periodística.

En el periodo comprendido entre 2006 y 2008, observamos diversas actitudes de los periodistas de Culiacán, diferentes a las del tipo de relación prensa-poder autoritaria. Los periodistas consideran actualmente reprobable, por ejemplo, combinar ejercicio periodístico con cargos públicos, así como aceptar sobornos. Los datos correspondientes al eje "entorno de violencia" revelaron los peligros del ejercicio periodístico en Culiacán. Desde la década de 1970, debido a las actividades del crimen organizado, Culiacán se ganó la reputación de ser una ciudad sumamente violenta. Fenómenos relacionados con el crimen organizado acontecen en la región: inseguridad, impunidad, corrupción, lavado de dinero y violaciones de los derechos humanos. Lo anterior tiene como resultado que los periodistas busquen protegerse con prácticas de periodismo precavido. Los resultados del análisis de los datos pueden abstraerse para conformar una idea general ${ }^{7}$

7 Es decir, un modelo o tipo ideal weberiano que tiene entre sus características ser abstracto (es decir, no existe tal cual), amoral y cuya función es heurística (Demers, 1998). Sobre el método del "modelo" como "tipo ideal", Demers hizo una revisión, motivada por la forma de utilizar el término "modelo" en la obra Four Theories of the Press, Siebert et al. (1963), donde emplean el término en su sentido normativo o moral. Demers (1998) propuso despojar de este sentido al término y usarlo en el sentido de tipo ideal, el cual "[se obtiene] acentuando unilateralmente uno o más puntos de vista y encadenando una multitud de fenómenos dados aisladamente, difusos y discretos, que se encuentran ya sea numerosos, poco numerosos o a veces no se encuentran, que se ordenan según los precedentes puntos de vista elegidos unilateralmente, para formar un esquema de pensamiento homogéneo. Empíricamente en 
de la práctica del periodismo basado en la autocensura de los periodistas por dos problemáticas:

1. La subsistencia económica de la empresa periodística (estas dependen económicamente de la publicidad gubernamental y de ciertas prácticas de clientelismo).

2. La falta de seguridad (los periodistas deben reportar y fotografiar los hechos cotidianos con precaución, debido al ambiente de violencia).

\section{LA RELACIÓN PRENSA-PODER}

\section{Y LA ECONOMÍA DE LOS MEDIOS EN CULIACÁN}

En el periodo de estudio (2006-2008), trascendió la permanencia de métodos sutiles de limitación del ejercicio periodístico: la censura económica -e. g. el "veto publicitario"-y el ofrecimiento de sobornos. Las protestas públicas de un grupo importante de periodistas de Culiacán contra la inoperancia de la Ley de Acceso a la Información Pública del Estado de Sinaloa (estos exigían una reforma que frenara la práctica de reservar indiscriminadamente la información pública, incómoda para las autoridades estatales) y la aparición de notas informativas con tratamiento imparcial sobre problemas sociales, fueron indicadores del nivel de independencia editorial de la prensa escrita sinaloense en este periodo. La ausencia de certámenes periodísticos organizados por el gobierno estatal coincide también con una aspiración de independencia editorial.

En Culiacán hay empresas periodísticas, así como periodistas, que siguen aprovechando una arraigada cultura de clientelismo político y, por otro lado, quienes se inclinan más por la denuncia de este tipo de prácticas perversas. En cuanto a los medios que aprovechan la cultura clientelista, su dependencia económica en la publicidad gubernamental es causa de un ambiente organizacional en el interior de la empresa periodística, en el que el conflicto de interés de origen económico es uno de los principales motivos de autocensura de los periodistas: el ambiente organizacional en este tipo de empresas periodísticas ocasiona que

ninguna parte se encontrará un semejante esquema en su pureza conceptual: es una utopía" (Weber citado por Demers, 1998). 
los periodistas de Culiacán practiquen la autocensura rutinariamente, con el propósito de realizar con menores dificultades su trabajo. Es decir, los periodistas que cubren temas políticos y sociales aprenden qué tipo de noticias suelen "entrar" en las ediciones diarias y cuáles no. De esta forma, periodistas, funcionarios públicos y directivos de este tipo de empresas periodísticas de Culiacán realizan distintas prácticas que convergen en la sumisión a un poder económico:

1. Los funcionarios públicos contribuyen con sus prácticas a reforzar una relación prensa-poder de colusión y subordinación de los medios. Las prácticas de los funcionarios públicos incluyen contratar espacios publicitarios de forma discrecional -muchas veces con el propósito de castigar o premiar a publicaciones-, reservar la información, tener injerencia en la agenda periodística y ofrecer beneficios externos a periodistas (sobornos). En 2004 hubo varios casos de violencia contra periodistas de parte de funcionarios públicos.

2. Las prácticas de los jefes y directivos de las empresas periodísticas son de subordinación al poder público. Las prácticas de directivos de los periódicos incluyen la venta de gacetillas, no perjudicar en las notas periodísticas a los clientes de publicidad y no exigir exclusividad a los reporteros, para mantener sus salarios bajos (los reporteros pueden complementar su trabajo periodístico laborando en oficinas públicas, lo cual compromete su independencia).

3. Las prácticas de los periodistas que cubren temas políticos y sociales incluyen no realizar periodismo de investigación -sino uno que enfatiza las declaraciones de los funcionarios y actores políticos-, autocensurarse y aceptar los beneficios externos que ofrecen los funcionarios, así como trabajos en oficinas públicas que comprometen su independencia debido a conflictos de interés.

\section{UN PERIODISMO CON PRECAUCIÓN}

El concepto de la debilidad del Estado mexicano puede descomponerse en distintos fenómenos que median el ejercicio de la libertad de prensa de los periodistas. En el caso del entorno de Culiacán, la debilidad del Esta- 
do implica fenómenos como la corrupción y la impunidad. Asimismo, el Estado no ha logrado impedir que haya altas tasas de incidencia de delitos de alto impacto y violencia contra periodistas. Ante la indefensión de éstos y de los propios policías, los funcionarios de gobierno han promovido entre los medios prácticas periodísticas (por ejemplo, la autocensura) que favorecen su imagen pública. La sociedad, por su parte, desconfía de las fuerzas públicas, de las autoridades y de la información oficial sobre seguridad, a la vez que demanda más información sobre seguridad y violencia. Los fenómenos del entorno ocasionan que los periodistas de Culiacán que cubren temas delicados, específicamente aquellos temas relacionados con seguridad, justicia y hechos policiacos, tengan miedo de ser víctimas de violencia. El miedo de estos ocasiona, a su vez, que aprendan a ejercitar el periodismo de forma precavida. Este conjunto de prácticas de periodismo precavido en Culiacán se basa en la autocensura y sus características son:

Ser receptor de amenazas: a pesar de intentar proteger la identidad de los periodistas, estos reciben mensajes de agresores potenciales. Las amenazas o informaciones anónimas se convierten en un criterio para decidir sobre qué autocensurarse. Un periodista de El Debate refirió que las amenazas contra periodistas aparecen cuando los medios de comunicación se interesan por un presunto criminal después de un hecho violento o una detención:

Cuando detienen a "equis" persona, que rápido se sabe, o por medio de los mismos policías, o por gente que llega al lugar o algo, que esa persona trabaja para "equis", no vamos a decir nombre, para "equis" capo o narco. Y ya desde ahí empiezan muchas veces por medio de los abogados que ellos traen. Mandan un emisario, en este caso a un abogado, por teléfono, no sé. Fíjate, es tan grande el poder que tienen esas gentes que a mí al celular me hablan. ¿Yo cuándo le doy el celular a nadie?8

Anónimo: el periodismo sobre temas delicados debe ser anónimo en varios sentidos. Los periódicos protegen la identidad de sus periodistas: suelen omitir el nombre del autor de la nota informativa cuando se tra-

8 Entrevista con A3, periodista de El Debate, 2008. 
ta de temas delicados. Un reportero del semanario Río Doce comentó sobre esta medida:

[...] Para nosotros es una cobardía. Algunos medios locales ya lo implementaron pero, de todos modos, cuando un narco, cuando un político te quiere fregar lo va a hacer, porque si tú escribes esa nota no son..., cómo te digo, “¿quién la escribió?”, o sea, es una falsa expectativa que digas "no la voy a firmar, le voy poner 'redacción' y no se van a dar cuenta”. Ellos saben quién hace y quién no hace. Entonces nosotros preferimos seguir poniendo nuestros nombres y finalmente es también responsabilidad de quienes estamos escribiendo. 9

Por su parte, los rostros de los policías, militares y peritos forenses son editados. En los últimos años (2005-2008), los reporteros gráficos han sido los periodistas más agredidos físicamente en Culiacán. Los agresores en este tipo de casos son usualmente agentes de corporaciones de seguridad pública.

Pragmático: las notas informativas de las secciones policiacas consignan exclusivamente "hechos policiacos", es decir, hechos violentos. Los periodistas no realizan periodismo de investigación. Un informante expresó que las notas informativas "carecen de la información 'analítica' que proporciona el periodismo de investigación" y las investigaciones periodísticas. Los periodistas tienen conciencia de que no deben tomar riesgos innecesarios. Un periodista de Noroeste opinó:

[...] no se realiza investigación sobre narcotráfico, es altamente riesgoso, además de que no hay quién te provea de ese tipo de información porque muchas oficinas están centralizadas en la ciudad de México; aquí hay únicamente oficinas de representación de la PGR ${ }^{10}$, por ejemplo. Entonces se cuida que toda la información sobre narcotráfico sea la que den las fuentes oficiales, es decir, PGR, SIEDO, pero nunca un documento filtrado, que sea de gente de dudosa reputación. 11

9 Entrevista con D2, periodista de Río Doce, 2008.

10 Procuraduría General de la República.

11 Entrevista con C1, periodista de Noroeste, 2007. 
Por su parte, un periodista de El Sol de Sinaloa explicó cómo suele ser el reporte de los hechos:

[...] no hay un lineamiento así de que te diga el director "vas a escribir esto, ¿no?”. Es simplemente el reportero que están... Conocen a los policías y en cierta manera conocen cómo está la relación de los distintos grupos que se mueven aquí en Culiacán [...]. De manera que por lógica tú sabes que no tiene caso irse más a fondo sino simplemente dar fe de los hechos: mataron a Fulano de Tal a tal hora y en tales circunstancias y nada más. ${ }^{12}$

Amarillista: las notas informativas se enfocan en la violencia, tienen discurso adjetivado, en ocasiones lenguaje vulgar, muestran imágenes perturbadoras y violan el principio de presunción de inocencia de los individuos, siempre y cuando esto no implique riesgos de amenazas.

Oficial: las notas informativas se alimentan de datos provenientes de autoridades y de la información recabada por los reporteros en el lugar de los hechos. Los datos oficiales son incuestionables por temor a represalias.

Ético por precaución e intuitivo: los periodistas acogen valores éticos, como la imparcialidad y el derecho a la privacidad de las personas involucradas en acontecimientos "policiacos", por conveniencia y protección después de la escalada de violencia. Los periodistas evitan "tomar partido", es decir, expresar juicios de valor dentro de las notas informativas, guían sus precauciones con intuiciones y creencias sobre lo que es prudente o de sentido común. Por ejemplo, los periodistas afirman que tras la escalada de violencia intentan tener mayor "sensibilidad" ante la información que está por publicarse. ${ }^{13}$ Los periodistas carecen de códigos escritos sobre seguridad que guíen sus prácticas; suelen seguir acuerdos verbales temporales basados en sus conocimientos sobre el entorno y en su sentido común.

Inexperto: la percepción del peligro y el estrés que conlleva esta profesión contribuye a que los periodistas sean típicamente adultos jó-

12 Entrevista con B1, periodista de El Sol de Sinaloa, 2007.

13 Entrevista con C2, periodista de Noroeste, y D1, periodista de Rio Doce, 2008. 
venes varones, menores de 35 años, con poca experiencia en el periodismo y que se presente alta rotación laboral.

\section{CONSIDERACIONES FINALES}

En este trabajo se propone una diferenciación entre lo que ocurre en el "centro" del país (caracterizado por zonas metropolitanas, como la del valle de México y la de Guadalajara) y lo que ocurre en las regiones del "interior" del país, afectadas por el crimen organizado: en las primeras son raros los casos de violencia contra periodistas, mientras que en las últimas se dan con frecuencia casos de homicidio, violencia y amenazas verbales contra periodistas. ${ }^{14}$ Se espera encontrar en investigaciones posteriores las mismas características descritas para la ciudad de Culiacán -las cuales se denominaron en este artículo "periodismo precavido"- en los estados mexicanos más afectados por la violencia relacionada con el crimen organizado (los que colindan con la frontera norte, así como con las costas del Pacífico y del Golfo).

El periodismo precavido practicado en Culiacán, una ciudad del interior de México, tiene mediaciones en distintos niveles (ver cuadro 1). En un nivel Estado-nación, la debilidad del Estado implica altos niveles de corrupción e impunidad, sobre todo en las regiones del interior del país. El gobierno produce y administra información, minimiza la violencia y, con una retórica maniquea, sus autoridades proponen la autocensura (IFEX, 2007) y no "magnificar la contracultura del narcotráfico y de la violencia". La sociedad, por su parte, demanda información sobre seguridad y violencia. El periodismo

14 Sin embargo, diversos casos de amenazas contra periodistas capitalinos hacen considerar que la precarización de la libertad de prensa, debido a la actividad del crimen organizado, incluye al centro del país. En abril de 2008, una reportera del periódico capitalino El Universal fue amenazada de muerte por un abogado por escribir sobre la detención de su cliente -un ex militar fundador de una organización delictiva- en un país extranjero. La agresión verbal a la reportera mereció comentarios de periodistas radiofónicos en cadena nacional, lo cual no suele ocurrir cuando se trata de reporteros del interior de la república. 


\section{CUADRO 1}

La debilidad del Estado

implica corrupción e impunidad

ierno y fuerza

públicas producen

información,

monitorean medios de

difusión y promueve

prácticas periodísticas

que lo ofrecen

y permite una alta incidencia de delitos

de alto impacto y de violencia

contra periodistas

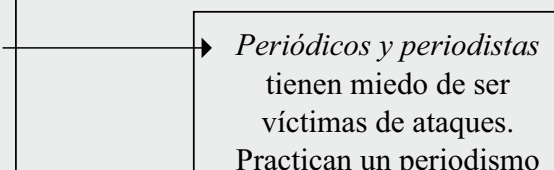

Practican un periodismo

basado en la autocensura

\begin{tabular}{|c|c|}
\hline $\begin{array}{c}\text { La sociedad } \\
\text { demanda } \\
\text { información } \\
\text { sobre seguridad } \\
\text { y violencia }\end{array}$ & $\begin{array}{c}\text { basado en la autocensura } \\
\text { Periodismo precavido: } \\
\text { Anónimo, } \\
\text { pragmático, ético, } \\
\text { oficial, amarillista, } \\
\text { intuitivo, inexperto }\end{array}$ \\
\hline
\end{tabular}

El cuadro resume el periodismo precavido practicado en la ciudad de Culiacán y sus mediaciones en distintos niveles. La violencia contra periodistas, especialmente contra reporteros gráficos, es frecuente, aunque no ha habido ningún caso de homicidio de periodistas en Culiacán desde 1987 ( sin contar el ataque contra el vocero de Seguridad Pública de Gobierno del Estado en 2007) y en Sinaloa desde 2005. Esto resulta paradójico debido a la alta incidencia de periodistas asesinados y desaparecidos en México entre 2005 y 2008.

precavido sobre temas delicados es, en resumen, lo que puede ser en términos económicos y de seguridad: periódicos y periodistas realizan un periodismo sobre temas delicados, mediado por la razón de mercado y cuyo valor principal es la sobrevivencia.

No obstante, son muchas las preguntas que surgen de estas conclusiones: por ejemplo, no es claro cuál es la función social de un 
periodismo precavido que tiene valores contradictorios y qué tan seguro es realmente, caracterizado en este artículo (así como las propias políticas de seguridad pública y nacional mexicanas y el actuar de los funcionarios del sector de seguridad) por los propios periodistas, para la sociedad y para el Estado.

\section{Bibliografía}

ACOSTA, M. (1999 [1994]). Los medios de comunicación y la educación ciudadana. Sala de Prensa, núm. 12, octubre, año II, vol. 2. Disponible en: www.saladeprensa.org.

ARTICLE 19 et al. (2008). Libertad de prensa en México: La sombra de la impunidad y la violencia. Misión internacional de documentación sobre ataques en contra de periodistas y medios de comunicación. México.

AStORGA, L. (2005). El siglo de las drogas. México: Random House Mondadori.

CARREÑO C. J. (2000). Cien años de subordinación / Un modelo histórico de la relación entre prensa y poder en México en el siglo XXI. Sala de Prensa, núm. 16, febrero, año III, vol. 2. Disponible en: www.saladeprensa.org/art102.htm.

Chalaby, J. K. (2000). New media, new freedoms, new threats. Gazette, vol. 62. London: Sage Publications, Thousand Oaks, pp. 16-29.

COMITÉ para la Protección de los Periodistas, CPJ (2006). Ataques a la prensa 2005. Nueva York, 43 pp.

DEMERS, F. (1998). Teorías normativas de la prensa y tipos ideales para interpretar los discursos sobre el periodismo. Comunicación y Sociedad, núm. 34. Guadalajara: Universidad de Guadalajara-Departamento de Estudios de la Comunicación Social.

FLORES Pérez, C. A. (2005). El Estado en crisis: crimen organizado y política. Desafios para la consolidación democrática, tesis de doctorado. México: UNAM. Consultada el 31 de agosto de 2008, www.funcionpublica.gob.mx/unam/2005/ ganadores/1_estado encrisis.pdf.

(FMB) FUNDACIÓN Manuel Buendía (1997). Bitácora de hechos 19941996. Consultada el 6 de octubre de 2008, www.mexicanadecomunicacion.com.mx/Tables/fmb/libexp/bth9496.htm, México. 
- (2006). Recuento de los daños, 1997-2005. Consultada el 19 de octubre de 2006, México, www.mexicanadecomunicacion.com.mx/ Tables/FMB/libertadexpresion/ indice.html.

HugheS, S. (2003). From the inside out. How institutional entrepreneurs transformed Mexican journalism. Harvard International Journal of Press/Politics, vol. 8 (3), 87-117.

(IFEX) INTERNATIONAL Freedom of Expression Exchange. (2007). Procuraduría General justifica la autocensura frente a los peligros crecientes; CENCOS exige al gobierno mejores garantías, 1 de agosto. Consultado el 19 de octubre de 2008, www.ifex.org/es/content/ view/full/85279/.

LÓPEZ, R. y Moreno, L. (2008, 3 de enero). 2773 ejecuciones en 2007, Milenio, México. Consultada el 20 de mayo de 2008, www.milenio. com/index.php/2008/01/03/170874/.

MARTíneZ, O. R. Barrera, J. A. N. Perafán, F. N. y Martínez, V. T. (1994). Análisis de los casos 1988-1994, Fundación Manuel Buendía-Unidad de Libertad de Expresión, México. Consultado el 1 de octubre de 2008, www.mexicanade comunicacion. com. mx/Tables/ $\mathrm{fmb} / \mathrm{libexp} / \mathrm{ac} 8894 . \mathrm{htm}$.

OROZCO, M. R. (2007). Relaciones prensa-gobierno en Tepic: hacia la caracterización de prácticas predominantes en el periodismo local en México, tesis para obtener el grado de maestra en comunicación. Guadalajara: Universidad de Guadalajara.

RED Periodismo de Calidad. (2006). Propuesta de indicadores para un periodismo de calidad en México (1a. ed.). México: Universidad Iberoamericana / Red Periodismo de Calidad / Organización de los Estados Americanos / Trust for Americas / Fundación Prensa y Democracia / Agencia de Estados Unidos para el Desarrollo Internacional, $143 \mathrm{pp}$.

REPORTEROS sin Fronteras. (2006, 31 de diciembre). Libertad de prensa, el año en cifras, París, 8 pp. www.rsf.org/article.php3?id_article $=20287$.

- (2008, 30 de diciembre), "Libertad de prensa: el año 2008 en cifras". Consultado el 7 de enero de 2009, http://www.rsf.org/article. php3?id_article $=29805$. 
SÁNCHEZ Ruiz, E. (1992). Medios de difusión y sociedad. Guadalajara: Universidad de Guadalajara-CEIC.

SIEBERT, F. S. Peterson, T. y Schramm, W. (1963). Four Theories of the Press, Illini Books. Urbana: University of Illinois Press.

TREJO Delarbre, R. (1995). Prensa y gobierno: Las relaciones perversas", en Comunicación y Sociedad, núm. 25-26, septiembre-abril. Guadalajara: Universidad de Guadalajara-Departamento de Estudios de Comunicación Social, pp. 35-55.

TrotTI, R. (dir.) (2006). Mapa de riesgos para periodistas. Miami: Sociedad Interamericana de Prensa, $225 \mathrm{pp}$.

WAISBORD, S. (2002). Antipress violence and the crisis of the state. Harvard International Journal of Press/Politics, vol. 7 (3), pp. 90109.

Entrevistas citadas

A3 periodista de El Debate

B1 periodista de El Sol de Sinaloa

C2 periodista de Noroeste

D1, D2 periodistas de Río Doce 